\title{
DESAIN BAHAN AJAR KOMPUTASI MATEMATIKA BERBANTUAN SOFTWARE MATHEMATICA UNTUK MENGEMBANGKAN KEMANDIRIAN BELAJAR MAHASISWA
}

\author{
Abdul Baist 1)*, M. Arie Firmansyah ${ }^{2)}$, dan Aan Subhan Pamungkas ${ }^{3)}$ \\ ${ }^{1,2)}$ Pendidikan Matematika, FKIP, Universitas Muhammadiyah Tangerang \\ Jl. Perintis Kemerdekaan I/33, Cikokol, Kota Tangerang, 15118 \\ ${ }^{3)}$ Pendidikan Matematika, FKIP, Universitas Sultan Ageng Tirtayasa \\ Jl. Raya Jakarta Km 4, Pakupatan, Serang, Banten, 42122 \\ *abdulbaist@umt.ac.id
}

\begin{abstract}
Abstrak
Dasar analisis numerik modern pada saat ini adalah komputasi matematika. Kemampuan penyelesaian permasalahan matematika melalui komputasi matematika perlu dimiliki mahasiswa saat ini. Fakta yang ditemukan di lapangan bahwa sebagian besar mahasiswa di Program Studi Pendidikan Matematika Universitas Muhammadiyah Tangerang mendapatkan nilai kurang dari B pada mata kuliah Komputasi Matematika. Kebutuhan bahan ajar yang dapat membantu mahasiswa dalam mempelajari komputasi matematika secara mandiri sangat diperlukan. Penelitian ini menggunakan metode pengembangan. Kemudahan yang dimiliki oleh software Mathematica dipilih dan digunakan dalam bahan ajar berbantuan software tersebut untuk membantu mahasiswa dalam mempelajari komputasi matematika secara mandiri. Hasil pengujian ahli didapat skor $80 \%$. Hasil pengujian skala kecil didapat skor $90 \%$. Kesimpulan yang didapat dari penelitian ini adalah bahan ajar komputasi matematika berbantuan software Mathematica untuk mengembangkan kemandirian mahasiswa penggunaannya masuk dalam kategori layak.
\end{abstract}

Kata Kunci: bahan ajar, software Mathematica, kemandirian.

\section{PENDAHULUAN}

Komputasi matematika dan algoritma numerik merupakan inti dari simulasi komputer. Berkat kecanggihan teknologi saat ini, aktifitas sains dapat dilakukan melalui simulasi komputer. Cara pandang baru ini menjadikan komputasi sebagai dasar analisis numerik modern (Yang, 2015).
Kemampuan dalam bidang komputasi matematika pada saat ini sangat diperlukan. Program Studi Pendidikan Matematika Universitas Muhammadiyah Tangerang menjadikan komputasi matematika sebagai mata kuliah. Komputasi matematika dipandang sebagai bekal yang perlu dimiliki oleh mahasiswa saat ini. Kelak mereka tidak 
hanya memiliki kemampuan menyelesaikan permasalahan matematika secara analitik tapi juga numerik.

Fakta yang ditemukan di lapangan, yaitu di Program Studi Pendidikan Matematika Universitas Muhammadiyah Tangerang, oleh Baist dan Pamungkas (2017) bahwa sekitar 70\% mahasiswa mendapatkan nilai kurang dari B pada mata kuliah Komputasi Matematika. Kesulitan yang mereka alami pada mata kuliah tersebut disebabkan oleh, di antaranya, kurangnya contoh, dan terlalu banyak teori. Mempelajari materi yang ada pada mata kuliah tersebut secara mandiri dirasakan sulit oleh mereka.

Pembelajaran secara mandiri merupakan sistem pembelajaran yang diterapkan di perguruan tinggi. Penjelasan yang diberikan oleh Schunk dan Zimmerman bahwa pembelajaran secara mandiri dapat memberikan dampak terhadap kemampuan mahasiswa dalam mengatur dirinya dalam proses belajar mengajar. Kemampuan tersebut menurut Zimmerman dapat digunakan sebagai alat adaptasi dalam mengatasi setiap perubahan yang terjadi. (Fadillah dan Baist, 2017).

Salah satu komponen penting dalam pembelajaran adalah bahan ajar. Bahan atau materi pelajaran yang digunakan oleh guru atau peserta didik tersusun secara sistematis tercakup di dalamnya kompetensi, tujuan, dan implementasinya (Pannen, Paulina, dan Purwanto, 2001; Prastowo, 2011). Bahan ajar yang dapat membantu mahasiswa dalam mempelajari komputasi matematika secara mandiri tentunya perlu diadakan berdasarkan masalah di atas. Ketersediaan bahan ajar tentang komputasi matematika yang mudah dipahami oleh mahasiswa jumlahnya tidak begitu banyak. Terlebih lagi bahan ajar komputasi matematika yang dapat membantu mahasiswa dalam menguasai komputasi matematika secara mandiri. Oleh karenanya diperlukan bahan ajar yang dapat memenuhi kebutuhan tersebut.

Software Mathematica dipilih untuk membantu mahasiswa dalam mempelajari materi yang ada pada mata kuliah Komputasi Matematika. Fitur yang beragam dan kemampuan yang luar biasa serta kemudahan dalam penggunaannya dimiliki oleh software Mathematica. Seperti yang diungkapkan oleh Abell dan Braselton (2004) bahwa software Mathematica memiliki kemampuan mengkombinasikan manipulasi simbolik, matematika numerik, luar biasa tampilan grafiknya, dan bahasa pemrograman yang canggih. Dibandingkan dengan Maple, Mathematica unggul dalam kecepatan dan kapabilitas; pembuatan prototipe dan eksplorasi dalam pemrograman fungsional (Zotos, 2007).

Berdasarkan uraian di atas, peneliti mengajukan suatu rumusan masalah yaitu "Bagaimanakah mendesain bahan ajar komputasi matematika berbantuan software mathematica untuk mengembangkan kemandirian mahasiswa?". Oleh karenanya, tujuan dari penelitian ini adalah mendesain bahan ajar komputasi matematika berbantuan software mathematica untuk mengembangkan kemandirian mahasiswa.

\section{METODE PENELITIAN}

Penelitian ini merupakan penelitian pengembangan (development research) dikarenakan penelitian ini bertujuan untuk menghasilkan bahan ajar yang dapat memudahkan mahasiswa untuk menggunakan bahan ajar tersebut dalam perkuliahan. Penelitian pengembangan merupakan penelitian yang bertujuan untuk mengembangkan dan menghasilkan produk pendidikan untuk mengatasi masalah 
pendidikan dan bukan untuk menguji suatu teori (Ruseffendi, 2005).

Penggunaan model pengembangan tipe 4-D diterapkan dalam penelitian ini. Model tersebut dikembangkan oleh Thiagarajan di mana model tersebut memiliki empat tahapan yang terdiri dari Define, Design, Develop, dan Disseminate (Nurhayati, 2017).

Validasi dilakukan oleh beberapa ahli, yaitu ahli media, ahli materi, dan ahli pendidikan. Setelah validasi dilakukan oleh ketiga ahli tersebut, selanjutnya dilakukan uji skala kecil. Lima mahasiswa Prodi Pendidikan Matematika Universitas Muhammadiyah Tangerang diminta untuk menggunakan bahan ajar tersebut sebagai bagian dari uji skala kecil.

Pengukuran penilaian media untuk masing-masing uji ahli menggunakan skala Likert. Ketiga ahli, yaitu ahli media, ahli materi, dan ahli pendidikan diminta utnuk mengisi lembar validasi yang terdiri dari beberapa item dengan kriteria sangat baik, baik, cukup, kurang, dan sangat kurang. Deskripsi hasil penilaian dihitung dengan rumus berikut:

Persentase Nilai Akhir $=\frac{\text { skor mentah }}{\text { skor ideal }} \times 100 \%$

skormentah : jumlah skor jawaban responden

skor ideal : jumlah skor jawaban tertinggi

Interpretasi dari hasil perhitungan rumus di atas menggunakan kriteria berikut ini:

Tabel 1. Kriteria Persentase

\begin{tabular}{c|c}
\hline Kriteria (\%) & Klasifikasi \\
\hline $80<\mathrm{P} \leq 100$ & Sangat kuat \\
\hline $60<\mathrm{P} \leq 80$ & Kuat \\
\hline $40<\mathrm{P} \leq 60$ & Cukup \\
\hline $20<\mathrm{P} \leq 40$ & Lemah \\
\hline $0<\mathrm{P} \leq 20$ & Sangat lemah \\
\hline
\end{tabular}

Sumber : Riduwan (2009)

\section{HASIL DAN PEMBAHASAN}

Desain awal bahan ajar komputasi matematika yang dihasikan dalam penelitian ini terdiri dari empat bab: Bab Pertama berjudul Pengenalan Mathematica; Bab Kedua berjudul Aljabar dan Kalkulus; Bab Ketiga berjudul Persamaan Diferensial, Deret, Vektor, dan Matriks; dan Bab Keempat berjudul Pemrograman dengan Mathematica.

Berikut ini tampilan bahan ajar tersebut.

- Media penyimpanan: Kertas 70 gr.

- Ukuran: 21,0 cm x 29,7 cm.

- Ketebalan: 99 halaman + cover.

- Format: Portable Document Format (PDF)

- Jenis huruf: Cambria

- Materi: Pengenalan Mathematica, Aljabar dan Kalkulus, Persamaan Diferensial, Deret, Vektor, dan Matriks, dan Pemrograman dengan Mathematica.

- Tampilan awal bahan ajar terdiri dari cover, kata pengantar, dan daftar isi.

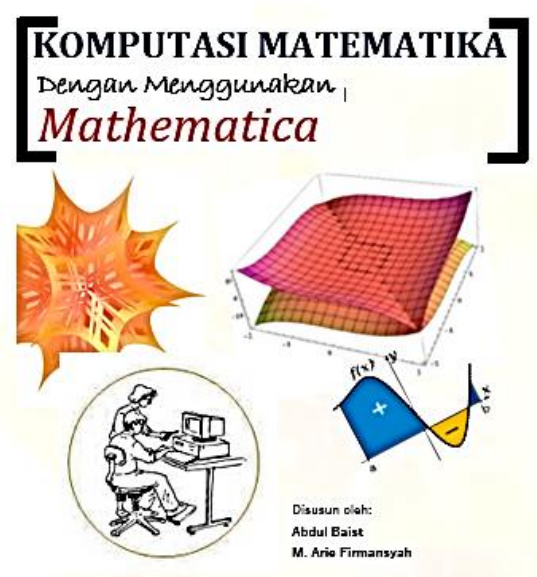

Fakultas Keguruan dan Ilmu Pendidikan Universitas Muhammadiyah Tangerang

Gambar 1. Tampilan Cover

Tampilan cover pada gambar 1 dibuat semenarik mungkin dengan jenis huruf yang 
bervariasi dan beberapa gambar yang berkaitan dengan matematika dan komputasi. Hal ini dilakukan agar pengguna buku, yaitu mahasiswa, tertarik melihatnya. Cover tersebut diharapkan dapat menggambarkan isi dari buku tersebut.

Gambar 2 dan gambar 3 merupakan desain untuk tampilan Kata Pengantar dan Daftar Isi. Tampilan warna warni pada tepi halaman diharapkan dapat memunculkan kesan luwes pada buku ini sehingga menghilangkan kesan monoton.

Pembuatan bahan ajar ini diusahakan untuk dibuat semenarik mungkin agar pengguna bahan ajar ini, khususnya yaitu mahasiswa, agar mereka dapat tertarik untuk menggunakan bahan ajar ini. Hal ini sejalan dengan prinsip VISUALS yang dikemukakan oleh Mukminan (dalam Nurseto, 2011) dalam mengembangkan media pembelajaran yang salah satunya adalah menarik (interesting).

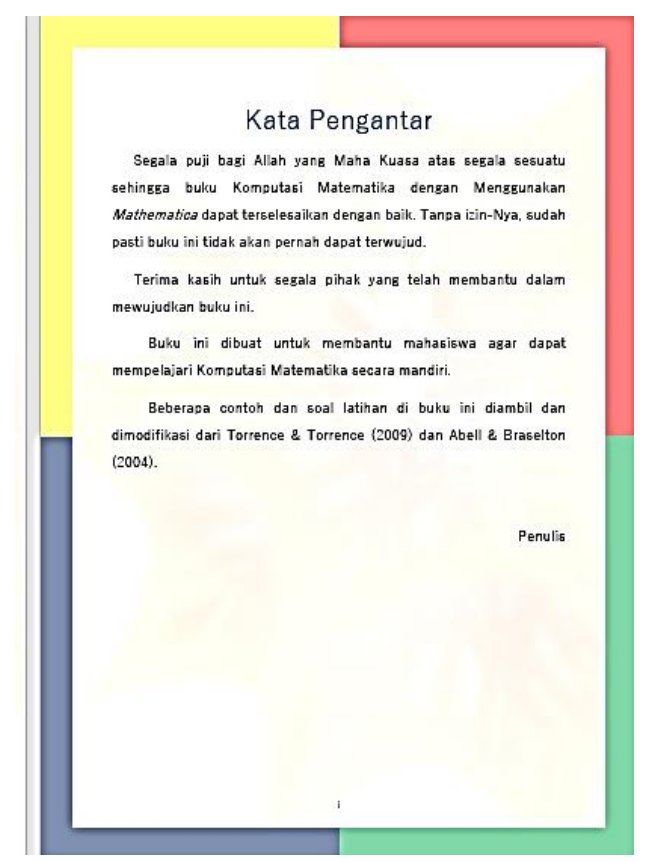

Gambar 2. Tampilan Kata Pengantar

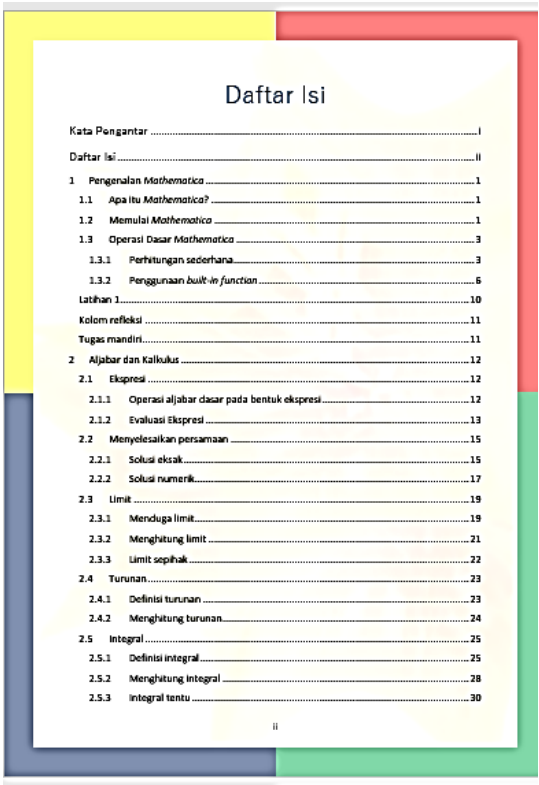

Gambar 3. Tampilan Daftar Isi

Bagian awal bab, ditunjukkan pada gambar 4, diawali dengan Standar Kompetensi, Kompetensi Dasar, dan Indikator dalam perkuliahan Komputasi Matematika. tujuan yang diharapkan dapat dicapai oleh mahasiswa dalam mempelajari bab tersebut.

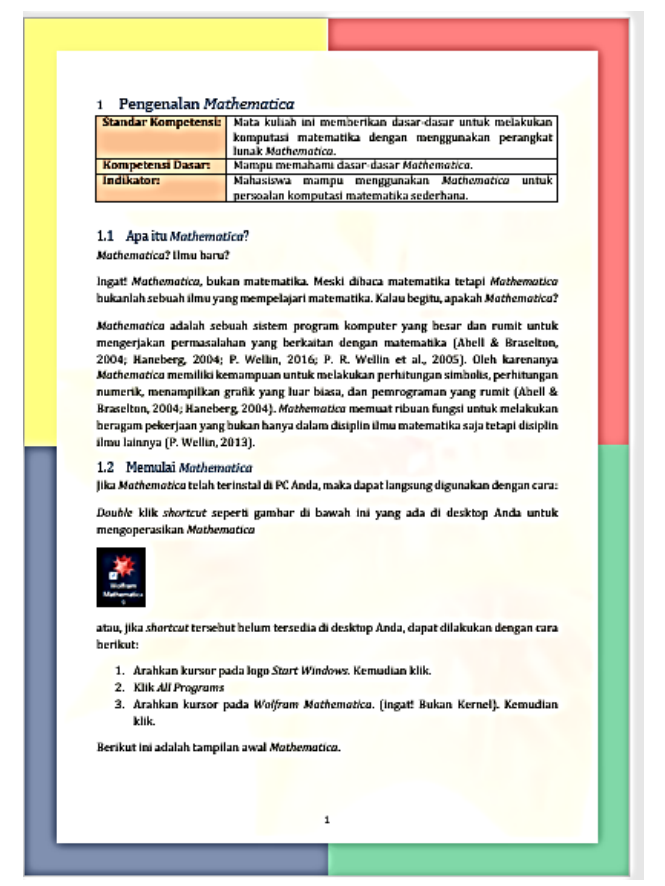

Gambar 4. Tampilan Bagian Awal Bab

Pada setiap akhir bab diberikan latihan seperti terlihat pada gambar 5. Kolom refleksi dan tugas mandiri juga diberikan 
pada setiap akhir bab seperti terlihat pada gambar 6.

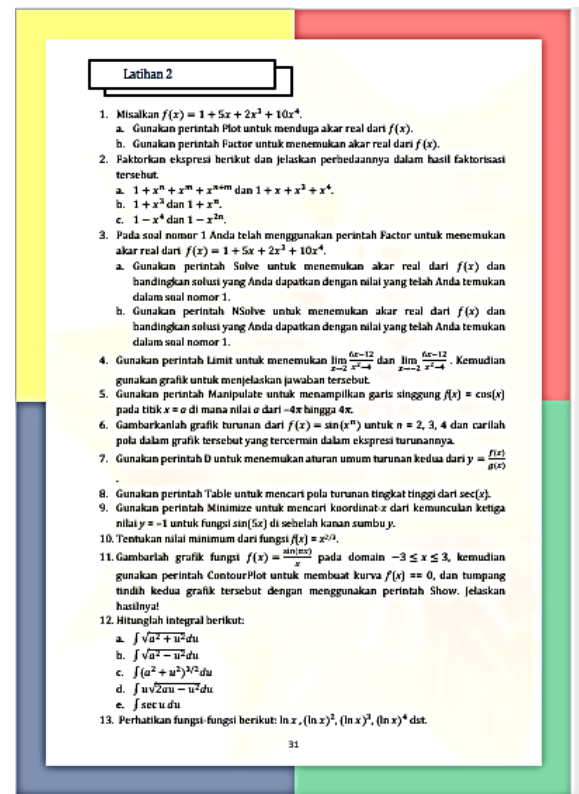

Gambar 5. Tampilan Bagian Latihan

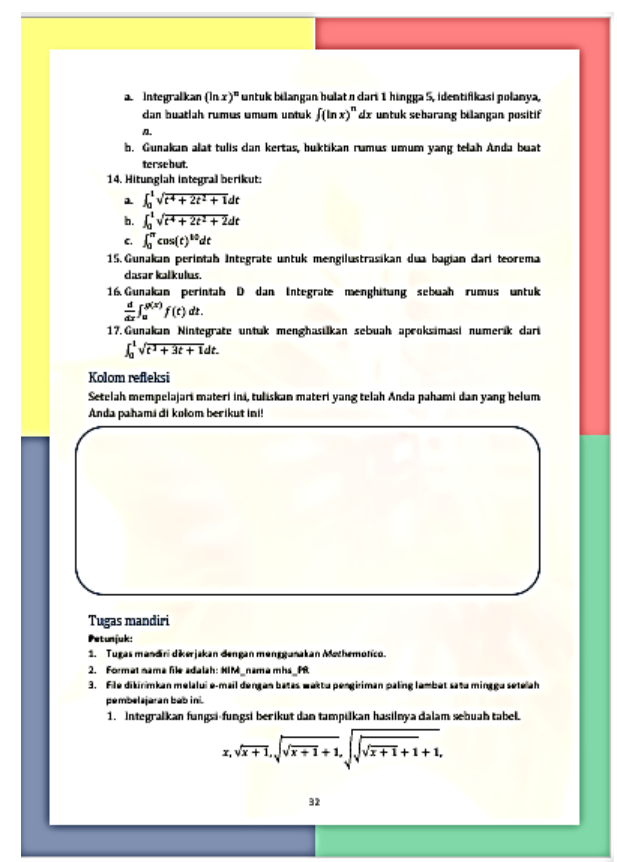

Gambar 6. Tampilan Bagian Kolom Refleksi dan Tugas Mandiri

Pemberian kolom refleksi dan tugas mandiri dalam bahan ajar ini bertujuan untuk membantu mahasiswa dalam melakukan proses kemandirian belajar. Chen (2011) mengungkapkan bahwa dalam proses kemandirian belajar, pembelajar perlu mengatur tujuan, membuat rencana, memilih strategi, memantau proses, dan mengevaluasi hasil belajar mereka.

Bahan ajar yang dihasilkan telah diujikan kepada tiga ahli, yaitu ahli media, ahli materi, dan ahli pendidikan. Tabel 2 memperlihatkan bagaimana hasil pengujian yang dilakukan oleh ketiga ahli tersebut.

Tabel 2. Hasil Validasi Ahli

\begin{tabular}{lll}
\hline Ahli & Persentase & Klasifikasi \\
\hline Media & $84 \%$ & Sangat Kuat \\
\hline Materi & $84 \%$ & Sangat Kuat \\
\hline Pendidikan & $75 \%$ & Kuat \\
\hline
\end{tabular}

Ahli media memberikan penilaian sebesar $84 \%$ yang berarti masuk dalam klasifikasi sangat kuat. Masukan yang diberikan oleh ahli media adalah warna background jangan terlalu polos. Hal ini dimaksudkan agar bahan ajar terlihat menarik.

Ahli materi memberikan penilaian sebesar $84 \%$ yang berarti masuk dalam klasifikasi sangat kuat. Ahli materi memberikan beberapa masukan di antaranya pemberian keterangan pada gambar, memperjelas tampilan output dari software Mathematica, dan perbaikan beberapa kesalahan dalam penulisan. Selain itu, ahli materi juga memberikan masukan untuk dibuatkan website pendukung dalam pembelajaran ini agar lebih interaktif.

Ahli pendidikan memberikan penilaian sebesar $75 \%$ yang berarti masuk dalam klasifikasi kuat. Masukan yang diberikan oleh ahli pendidikan adalah penambahan glosarium dan indeks. Diharapkan dengan penambahan tersebut dapat memudahkan pengguna untuk mengetahui istilah-istilah yang ada dalam bahan ajar dan mencari kata yang terdapat dalam bahan ajar. 
Perbaikan bahan ajar dilakukan setelah validasi oleh ketiga ahli selesai. Masukan yang diberikan oleh ketiga ahli menjadi acuan dalam melakukan perbaikan untuk bahan ajar. Seluruh masukan yang diberikan oleh ahli materi telah direalisasikan, kecuali pembuatan website. Keterbatasan waktu yang dimiliki oleh peneliti mengakibatkan pembuatan website belum dapat terwujud.

Setelah perbaikan untuk bahan ajar tersebut selesai dilakukan, maka dilanjutkan dengan pengujian skala kecil. Pengujian dalam skala kecil dilakukan terhadap lima mahasiswa Program Studi Pendidikan Matematika Universitas Muhammadiyah Tangerang. Penilaian yang didapatkan dari pengujian skala kecil tersebut sebesar $90 \%$. Hasil ini berada pada klasifikasi Sangat Kuat.

Terdapat beberapa masukan yang diberikan oleh mahasiswa dalam pengujian skala kecil. Mereka melihat bahwa masih terdapat simbol yang kurang jelas dalam bahan ajar tersebut. Mereka berharap penggunaan model tulisan dibuat lebih menarik. Masukan tersebut tentunya sangat bermanfaat agar bahan ajar ini menjadi lebih baik lagi.

\section{SIMPULAN}

Penelitian ini telah menghasilkan sebuah bahan ajar yang bertujuan untuk mengembangkan kemandirian mahasiswa pada mata kuliah Komputasi Matematika. Bahan ajar ini terdiri dari empat bab. Bab pertama berjudul Pengenalan Mathematica, bab kedua berjudul Aljabar dan Kalkulus, bab ketiga berjudul Persamaan Diferensial, Deret, Vektor, dan Matriks, dan bab keempat berjudul Pemrograman dengan Mathematica. Setiap bab diakhiri dengan Latihan, Kolom Refleksi, dan Tugas Mandiri. Bagian bab tersebut bertujuan untuk membantu mahasiswa dalam mengembangkan kemandirian belajar mereka.

Proses pengembangan bahan ajar dalam penelitian ini telah melalui proses pengujian validasi oleh tiga ahli, yaitu ahli media, ahli materi, dan ahli pendidikan. Penilaian yang diberikan oleh ahli media sebesar $84 \%$ yang termasuk dalam klasifikasi sangat kuat. Hasil penilaian tersebut sama seperti penilaian yang diberikan oleh ahli materi. Sementara itu ahli pendidikan memberikan penilaian sebesar $75 \%$ yang berarti termasuk dalam klasifikasi kuat. Masukan yang diberikan oleh para ahli telah dilakukan kecuali masukan tentang pembuatan website yang diberikan oleh ahli materi karena keterbatasan waktu.

Pengujian skala kecil yang dilakukan kepada 5 mahasiswa diperoleh skor $90 \%$ yang berarti termasuk dalam klasifikasi sangat kuat. Meski begitu masih terdapat masukan yang diberikan oleh mahasiswa, yaitu masih adanya simbol yang kurang jelas dalam bahan ajar tersebut. Mereka juga menginginkan agar tulisan dibuat lebih menarik.

Berdasarkan hasil pembahasan di atas maka produk bahan ajar yang dikembangkan dalam penelitian ini, yaitu berupa bahan ajar mata kuliah Komputasi Matematika untuk mengembangkan kemandirian belajar mahasiswa, layak untuk digunakan.

\section{UCAPAN TERIMA KASIH}

Terima kasih kami sampaikan kepada Kementerian Riset, Teknologi, dan Pendidikan Tinggi yang telah memberikan dana penelitian melalui hibah Penelitian Dosen Pemula (PDP). 


\section{DAFTAR PUSTAKA}

Abell, M.L., dan Braselton, J.P. 2004. Mathematica by Example. California: Elsevier Academic Press.

Baist, A., dan Pamungkas, A., S. 2017. "Analysis of Student Difficulties in Computer Programming”. Volt Jurnal Ilmiah Pendidikan Elektro. Vol. 2 (2), pp: 81-92.

Cheng, E. C. K. 2011. "The Role of Self-regulated Learning in Enhancing Learning Performance". The International Journal of Research and Review. Vol. 6 (1), pp: 1-16.

Fadillah, A., dan Baist, A. 2017. "Hubungan Motivasi dan Perilaku Terhadap Hasil Belajar Mata Kuliah Matematika Ekonomi”. Prima Jurnal Pendidikan Matematika. Vol. 1 (1), pp: 43-48.

Nurhayati, N. 2017. "Pengembangan Perangkat Bahan Ajar pada Pembelajaran Matematika Realistik Indonesia untuk Meningkatkan Kemampuan Komunikasi Matematis Mahasiswa". Fibonacci: Jurnal Pendidikan Matematika dan Matematika. Vol. 3 (2), pp: 121-136.

Nurseto, T. 2011. "Membuat Media Pembelajaran yang Menarik". Jurnal Ekonomi dan Pendidikan. Vol. 8 (1), pp: 19-35.

Pannen, Paulina, dan Purwanto. 2001. Penulisan Bahan Ajar. Jakarta: Pusat Antar Universitas untuk Peningkatan dan Pengembangan Aktivitas Intruksional Ditjen Dikti Diknas.

Prastowo, Andi. 2011. Panduan Kreatif Membuat Bahan Ajar Inovaif. Jogjakarta: Diva Press.

Riduwan. 2009. Rumus dan Data dalam Analisis Statistika. Bandung: Alfabeta.

Ruseffendi, E.T. 2005. Dasar-dasar Penelitian Pendidikan dan Bidang Non Eksakta Lainnya. Bandung: Tarsito.

Yang, Xin-She. 2015. Introduction to Computational Mathematics. London: World Sientific Publishing.

Zotos, Kostas. 2007. Performance comparison of Maple and Mathematica. Applied Mathematics and Computation. Vol. 188 (2), pp: 1426-1429. 
FIBONACCI : Jurnal Pendidikan Matematika dan Matematika

Volume 5 No. 1 Bulan Juni Tahun 2019 